\title{
Progressivity and the Re-Ranking Effect of Healthcare Financing in South East Nigeria
}

\author{
Nkeiru Joy Onyema \\ Department of Economics, University of Nigeria, Nsukka-Nigeria \\ Aduku, Ebikabowei Biedomo \\ Department of Economics, University of Nigeria, Nsukka-Nigeria \\ Richardson Kojo Edeme \\ Department of Economics, University of Nigeria, Nsukka-Nigeria \\ Email: richard.edeme@unn.edu.ng
}

Received: 5 August 2019; Revised: 10 September 2019; Accepted: 27 September 2019; Published: 8 October 2019

\begin{abstract}
This study adopts the Lerman and Yitzhaki approach to measure progressivity and re-ranking effects in health care financing in South East Nigeria. Result supports the existence of regressive healthcare payments. Households that spend more to healthcare financing are unable to maintain their original social status due to net income declining below prepayment income. This could certainly be catastrophic as it takes a huge proportion of the household's income, leaving households with insignificant amount on other basic needs. The in the region should develop and implement healthcare policy that can support healthcare spending of the poor households to prevent more people falling deeper into the poverty trap.
\end{abstract}

Keywords: Healthcare financing, Progressivity, Re-Ranking effect

\section{Introduction}

In recognition of the importance of universal access coverage and equity in healthcare to achieve sustainable human development, WHO (2010) adopted World Health Report that ensures universal health coverage by all countries. Inspite of this, various low and medium income countries are still grappling with challenges such as poor financial protection to households, thus making it difficult to meet the healthcare challenges of the people, especially the vulnerable. Various government have highlighted the importance of reducing the inequity in healthcare financing by improving healthcare financing mechanisms that will promote greater access to health care services and protecting families from debt traps (Mutangadura, et al, 2009).

Financing of healthcare is often assessed based on equity among others such as feasibility, efficiency and sustainability. Equity in healthcare financing ensures that individuals contribute to healthcare financing according to their ability to pay and benefit from such service (Yu, et al, 2008, Asante, et al, 2014, Asante, et al, 2016)). An equitable healthcare financing system in this regard is channeling subsidies from the rich to the poor and from the healthy to the ill. The concern in analyzing healthcare financing is whether it is having progressive, regressive, proportional or rank-ranking effect. Healthcare financing system is progressive when the rich pay more as a proportion of income than the poorer groups. When this happens, the healthcare system is sensitive to the differences in income of healthcare consumers (Ataguba \& Akazili, 2010). The systems of healthcare financing profoundly determine the functioning of the healthcare system, especially regarding the equity of the financial burden of healthcare and the accessibility of health services for different groups of a population.

In Asia, few countries such as Thailand, Malaysia and Srin Lanka maintain a pro-pro distribution of health care benefits and progressive financing. But the same cannot be said of developing countries where health care financing benefits the rich more than the poor Asante, et al, 2016). African countries are still struggling with the challenge of how to devise health policies and healthcare systems that can ensure equity in access to adequate healthcare. Concerns about inequity in healthcare financing are widespread in low-income and 
middle-income countries and regions within countries which have led to calls for effective strategies to improve equity. In South-east region of Nigeria, equity in health care financing has witnessed little improvement, despite improvement in public health spending in the last decade. The region is still characterized by inability of majority of the citizens not able to afford quality health care with majority of the expenditure coming from individuals. There is also wide disparity in health status, service delivery and healthresource availability (Omoluabi, 2014). Health care is provided by wide range of healthcare providers in both the public and private sectors, such as public facilities managed by federal, state, and local governments, private for-profit providers, None Governmental Organizations (NGOs), community-based and faith-based organizations, and traditional healthcare givers. Healthcare services are hospital-based with its technology being derived by bureaucracy and specialization. The public hospitals are concentrated majorly in the urban area which has resulted to inequality between those in the urban and rural areas (Ademiluyi \& Aluko-Arowolo, 2009). According to Uzochukwu, Onwujekwe \& Ezumah (2014), staff availability and distribution is not equitable and has resulted to over concentration of healthcare workers in the urban areas to the detriment of the rural settlements, where over $70 \%$ of the population resides It has been argued that these among contributes to a large extent to poor healthcare status. The major challenges include gender inequity in healthcare financing and variations in healthcare financing equity.

Though, progress has been made in reducing gender equality in areas such as education, inequity in healthcare financing continue to plague the regions and states within regions and there is lack of evidence in progressivity and re-ranking effect of health care financing. Polices that will translate efforts towards achieving equity in healthcare financing into reality requires empirical evidence which is the concern of this study Several studies including Wouters, Cylus, Yang, Thomson \& McKee (2016), John, Agada-Amade, Oyibo \& Ugwu (2015), Ghosh (2014) have assessed the financing mechanisms in different regions and country based on equity, feasibility, efficiency and sustainability with mixed findings, there is lack of empirical evidence on the equity aspect of healthcare financing, specifically on South East region of Nigeria. This study would therefore, complement previous studies and contribute to the stock of literature by exposing how healthcare payments nave re-ranked households in different socio-economic class in the region.

The paper is structured as follows. Section 1 which is the introduction presents an overview of healthcare financing status in developing countries and South east region of Nigeria while section 2 reviewed theoretical and empirical literature. Section 3 presents that and methodological framework while section 4 is results and discussion of empirical findings. The paper is rounded off in Section 5 with concluding remaks.

\section{Review of Literature}

The theoretical excursion on the assessment of the benefit of public health care financing accrures to citizens in the society was laid by the Marxists. It is opined that spending on healthcare should be focus on maximizing the outcome for the less privileged in the society. The worst-off are individuals are those of the lowest income that they have the least amount of social and economic opportunity. They are also categorized as the group of individuals who may have the worst health condition if there was no government intervention (Mattisson, 2017). Drawing evidence from China, Singapore, South Africa, and the United States of America, Almasiankia, Kavosi, Keshtkaran, Jafari, \& Goodarzi (2015) try to measure the equity in health system financing in urban and rural Iran between 2001 and 2010. With the the Kakwani index, findings indicate regressivity in out-of pocket payments for both rural and urban households. But there was progress in health insurance premium payments in rural areas. Chen, Fang, Wang, Wang, Zhao, \& Si (2015) focused on how the benefits from government healthcare subsidies in China were distributed among the citizen and found inequitable distribution of government healthcare subsidies. The rich generally reap larger benefits from the subsidized healthcare system than the poor. A larger chunk of the health care subsidies were used to build facilities that benefit the rich. This did not demonstrate inequality-reducing effects in health care financing in the different regions.

Focusing on the impact of health policy changes on equity of financing among households in India, Mondal (2014) used four rounds of national sample survey (NSS) data on consumer expenditure. Wagstaff and Aronson, Johnson, and Lambert decomposition method of redistributive effect was employed and results revealed out-of pocket expenditure had vertical effect on income redistribution, which increased by 15 percent between 1994 and 2004, and plummeted by 80 per cent in 2012. This outcome is an indication that public health care spending had more impact on low income group and produce higher equity in out-of-pocket spending. On the contrary, Wagstaff (2001) opine that a key dimension in measuring the performance of health system is the fairness of its financing system. While measuring the performance of different countries

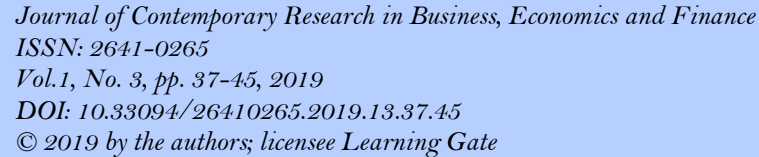


by rank, it was noticed that given WHO interpretation, it is difficult to discriminate between horizontal inequality and progressiveness or regressiveness because it is possible for household with the level of income to spend differently on healthcare or household with different income to spend different proportions of their income on health care. Akaziliet, et al (2012) further assessed the benefit-incidence of health care financing and found that in Ghana, the healthcare financing system was progressive in while the distribution of total benefits from public and private health services was pro-rich. Moreover, primary health care services were pro-poor and evenly distributed, although a number of access constraints contributed to inequities in the distribution of health service benefits. Burger, et al (2012) tries to ascertain if public health financing and access to healthcare services was more or less pro-poor over the years in South Africa. The results indicate that public health financing was more pro-poor between 1993 and 2008, with an increase in the share of public clinic and hospital financing allocated to the poor.

Another area of focus in equity in health care financing is universal coverage. In determining the implications for universal coverage of equity in health care financing in Ghana, South Africa, and Tanzania, Mills, et al (2012) analyzed the mechanisms for progressivity in health-care financing, catastrophic spending on health care and the distribution of health-care benefits. Findings indicate that out-of-pocket payments were regressive. Overall, distribution of health care service benefited the rich more than the poor. Moradi (2012) however noticed some degree of descending progressivity in urban areas while in rural areas there was evidence of slight improvement. There was evidence that primary health care financing is pro-poor. In an earlier study, Abu-Zaineh, Mataria, Luchini \& Moatti (2008) analyzed the redistributive effect and progressivity associated with health care financing schemes in Palestine. Bootstrap method was employed and found pro-rich and regressive feature of out-of-pocket payments in both aggregate and disaggregate approaches. Or, Jusot \& Yilmaz (2008) estimated the impact of healthcare funding system on social inequities in health care use in Europe using data from national surveys. It was concluded that primary care services was essential in reducing social inequities in health care utilization in the society.

Asante, et al (2016) alludes that eventhough health care reforms in low and middle income countries have focused on achieving equity in financing, its delivery health care financing benefits the rich more than the poor. The overall evidence suggests that there are bottlenecks in making health care more accessible and affordable to the poor.

\section{Materials and Methods}

The study utilized Generalized Household survey data extracted from the National Living Standard Survey. It is a nationally representative survey and contains information on household characteristics. Gini coefficient is used as an inequality index, it has been criticized by Gisbert, de la Vega \& Urrutia, (2010) due to its inability to additively decompose between group and within group terms or even aggregative. Given its linear structure, the index is insensitive to changes in the distribution of income, and lacks the possibility to accommodate value judgments. To overcome this, the single-parameter Gini or S-Gini coefficient has been proposed as most appropriate. The single-parameter measures the degree of relative sensitivity to transfers at different rank orders of people in a given society. The measure keeps all of the quality properties of inequality measures alongside all the primary properties of the original Gini index stated above. The index generally explains class of social evaluation functions that are ordinarily captured by the S-Gini coefficient representing the overall income, $G_{y}$. It is functionally represented as:

$$
G_{Y}=1-\frac{1}{\mu_{Y}} \sum_{i=1}^{s}\left(Y_{i}^{y}\right)\left(\gamma_{i}^{y}\right)\left(W_{i}^{y}\right)
$$

$\mathrm{G}_{\mathrm{Y}}=\mathrm{S}-\mathrm{Gini}$ coefficient representing the overall income

$\mu_{Y}=$ overall mean income

$\mathrm{s}=$ the number of income units, which is arranged in an increasing order of overall mean income and, is represented by y as indicated in the superscript of the respective vectors

$Y_{i}^{y}=$ overall income of the $i^{\text {ih }}$ unit

$\gamma_{i}^{y}=$ frequency weight of the overall income of the $i^{i n}$ unit

$W_{i}^{y}=$ rank-dependent weights 
The estimated quintile of the $i^{\text {ih }}$ unit is, $\hat{Q}_{i}^{y}=(2 S)^{-1} \sum_{j=1}^{i}\left(\gamma_{j}^{y}+\gamma_{j-1}^{y}\right)$ and $S=\sum_{j=1}^{s} \theta_{j}^{y}$ with $\theta_{0}^{y}=0$. The estimated rank-dependent weights, $W_{i}^{y}$ would be $\widehat{W}_{i}^{y}=(S)^{-1} v\left(1-\widehat{Q}_{i}^{y}\right)^{v-1}$. v is the parameter which determine $\widehat{W}$ - curve.

One advantage of this Gini is that members are also translatable functions and, therefore, can be used to derive absolute ethical inequality indices (Gisbert, de la Vega \& Urrutia, 2010). The S-Gini in a parametric way introduces the inequality aversion as a form of capturing the opinions of a moral observer (Donaldson and Weymark 1980, 1983; Yitzhaki 1983). But this generalization is not able to capture the entire range of opinions or attitudes sensitive to what happens with high incomes in the society, particularly in developing economies like Nigeria. Thus, the extended Gini index became relevant in order to provide a holistic presentation of the fact that different people can have different inequality aversions. The proposed extended Gini coefficient by Yitzhaki (1983) is:

$$
\begin{aligned}
& G(v)=1-v(v-1) \int_{0}^{1}(1-\varphi)^{v-2} L(\varphi) d \varphi \\
& =1-\frac{v}{\mu_{x}} \int_{0}^{\infty} x[1-K(x)]^{v-1} k(x) d x
\end{aligned}
$$

For the purposes of decomposition, equation (3) can be written in the covariance format as:

$=-\frac{v}{\mu_{x}} \operatorname{cov}\left(x,[1-K(x)]^{v-1}\right)$.

where $v$ is a parameter for inequality aversion and $L(\varphi)$ is the Lorenz curve of income. The coefficient $G(v)$ is defined for $\mathrm{v}>1$ and, is equivalent to the original Gini coefficient when $\mathrm{v}=2$. In that case, the policy authority does not have aversion if inequality occurs at the low or high ranks of the distribution due to healthcare payment. But if $\mathrm{v}>2$, then it means that the policy authority has pro-poor inequality aversion. However, when $\mathrm{v}$ approaches $\infty$, then there an increasing concern about the welfare of the poorest person in the population. A primary determining factor of $\mathrm{v}$ is the policy authority's level of fair-mindedness in the society.

This study adopts the Lerman \& Yitzhaki (2001) model of progressivity of healthcare payment. The model begins with the Musgrave \& Thin (1948) index of effective progression, which measures the level by which the form of healthcare payment leads to a movement towards equality from the distribution of post-healthcare payment income. This is scenario illustrated as:

$$
R E=G_{b p}-G_{a p}
$$

$\mathrm{RE}=$ Redistributive effect

$\mathrm{G}_{\mathrm{bp}}=$ Gini index of pre-healthcare payment income

$\mathrm{G}_{\mathrm{ap}}=$ Gini index of post-healthcare payment income

Equation (5) indicates that the redistributive effect is generated by subtracting post-healthcare payment Gini index from the Gini index of pre-healthcare payment income. If the value is $>0$, then healthcare payment structure reduces income inequality in the redistribution after paying for healthcare. The converse will be the case when the value is $<0$, implying that the system of healthcare payment is proportional. In line with the Lerman and Yitzhaki (1984) Gini index, equation (5) can be written in another form as:

$$
G=\frac{2 \operatorname{cov}(y \varphi)}{\bar{y}}
$$

$\mathrm{y}=$ income, $\varphi=$ ascending order ranked cumulative distribution of income, $\bar{y}=$ mean income. Equation (6) expressed that the Gini index as two times the normalized income and rank. In accordance with this covariance method, equation (5) can be written as:

$G_{b p}-G_{a p}=2 \operatorname{cov}\left(x_{b p}, \varphi_{b p}\right)-2 \operatorname{cov}\left(x_{a p}, \varphi_{a p}\right)(7)$

$x=\frac{y}{y}$, Lerman \& Yitzhaki (2001), by adding and subtracting $2 \operatorname{cov}\left(x_{b p}, \varphi_{b p}\right)$ or $2 \operatorname{cov}\left(x_{a p}, \varphi_{a p}\right)$ decomposed equation (7) into re-ranking effect (as a result of change in individuals ranks in the society) and healthcare payment progressivity (as a result of change in income due to healthcare payment). The decomposition is as shown concisely as:

$$
G_{b p}-G_{a p}=2 \operatorname{cov}\left(x_{b p}-x_{a p}, \varphi_{b p}\right)+2 \operatorname{cov}\left(x_{a p}, \varphi_{b p}-\varphi_{a p}\right)(8 \mathrm{a})
$$

or in a more detailed form as:

$$
G_{b p}-G_{a p}=2\left[\operatorname{cov}\left(x_{b p}, \varphi_{b p}\right)-\operatorname{cov}\left(x_{a p}, \varphi_{b p}\right)\right]+2\left[\operatorname{cov}\left(x_{a p}, \varphi_{b p}\right)-\operatorname{cov}\left(x_{a p}, \varphi_{a p}\right)\right](8 \mathrm{~b})
$$

Equation (8) can also be written in another form as: 


$$
G_{b p}-G_{a p}=2 \operatorname{cov}\left(x_{b p}-x_{a p}, \varphi_{a p}\right)+2 \operatorname{cov}\left(x_{b p}, \varphi_{b p}-\varphi_{a p}\right)
$$

The major difference between equations (8) and (9) is that both the progressivity and re-ranking components in equation (8) are always positive, but it may not always be positive in equation (9). From equation (8), it can be deduced that the distributive effect comprises of two parts. The first part $\left\langle 2 \operatorname{cov}\left(x_{b p}-x_{a p}, \varphi_{b p}\right) \operatorname{OR} 2\left[\operatorname{cov}\left(x_{b p}, \varphi_{b p}\right)-\operatorname{cov}\left(x_{a p}, \varphi_{b p}\right)\right]\right\rangle$ is the difference between before healthcare payment distribution Gini index and index of concentration of after healthcare payment income distribution (the pre healthcare payment income is the ranking variable in the later case). This is the same with the Kakwani (1977) index of progressivity, measuring vertical equity (Ichoku, Fonta \& Leibbrandt, 2011). On the other hand, the second part is the difference between the after-healthcare payment concentration index and the Gini index of the post-healthcare payment distribution. It is the re-ranking component $(\phi)$. Equation (9) explains that the redistributive effect is made up of the progressivity component (that is, covariance between the difference in before and after healthcare payment income and, the after-healthcare payment rank), and the re-ranking component (that is, the covariance between the income before healthcare payment and, the before and after healthcare payment rank difference). The components of the decomposition analysis are the prepayment Gini index $\left(\mathrm{G}_{\mathrm{bp}}\right)$, post-payment Gini index $\left(\mathrm{G}_{\mathrm{ap}}\right)$, the measure of progressivity or vertical equity $(\mathrm{V})$, the index of re-ranking $(\mathrm{R})$ and the composite index $(\mathrm{V}-\mathrm{R})$, which according to the Lerman-Yitzhaki framework is identical to the pre-payment Gini index minus the post-payment Gini index $\left(G_{b p}-G_{a p}\right)$. v is kept within the boundaries of $1.5-6$ with a threshold value of 2 when the social decision-maker is inequity neutral in healthcare financing. Put differently, whether inequity occurs below the mean or above the mean of the distribution, decision-makers are not worried. If $\mathrm{v}<2$, there is inequality in the preference of the policy-maker but if $\mathrm{v}>2$, then policymaker is inequity averse. The higher the value of $\mathrm{v}$, the more the policy-maker is averse to inequity in health care financing in the disadvantaged group.

\section{Results and Discussion}

The distribution of personal characteristics of the respondents is reported in Table 1

Table 1.

Personal characteristics of the respondents

\begin{tabular}{|c|c|c|c|c|c|c|c|c|c|c|c|c|}
\hline & \multicolumn{2}{|l|}{ Abia } & \multicolumn{2}{|c|}{ Anambra } & \multicolumn{2}{|c|}{ Ebonyi } & \multicolumn{2}{|c|}{ Enugu } & \multicolumn{2}{|l|}{ Imo } & \multicolumn{2}{|c|}{ SEZone } \\
\hline & Freq. & $\%$ & Freq. & $\%$ & Freq. & $\%$ & Freq. & $\%$ & Freq. & $\%$ & Freq. & $\%$ \\
\hline \multicolumn{13}{|l|}{ Gender } \\
\hline Male & 491 & 85.54 & 424 & 83.46 & 487 & 85.44 & 446 & 82.59 & 434 & 85.94 & 2,282 & 84.61 \\
\hline Female & 83 & 14.46 & 84 & 16.54 & 83 & 14.56 & 94 & 17.41 & 71 & 14.06 & 415 & 15.39 \\
\hline Total & 574 & 100 & 508 & 100 & 570 & 100.00 & 540 & 100 & 505 & 100 & 2,697 & 100 \\
\hline \multicolumn{13}{|l|}{ Age Group } \\
\hline 25-29 years & 1 & 0.17 & - & - & 2 & 0.35 & 3 & 0.56 & 4 & 0.79 & 10 & 0.37 \\
\hline $30-34$ years & 9 & 1.57 & 8 & 1.57 & 17 & 2.98 & 16 & 2.96 & 10 & 1.98 & 60 & 2.22 \\
\hline 35-39 years & 44 & 7.67 & 33 & 6.50 & 37 & 6.49 & 36 & 6.67 & 28 & 5.54 & 178 & 6.60 \\
\hline $40-44$ years & 64 & 11.15 & 52 & 10.24 & 59 & 10.35 & 65 & 12.04 & 45 & 8.91 & 285 & 10.57 \\
\hline $45-50$ years & 68 & 11.85 & 63 & 12.40 & 62 & 10.88 & 61 & 11.30 & 57 & 11.29 & 311 & 11.53 \\
\hline $51-54$ years & 64 & 11.15 & 71 & 13.98 & 82 & 14.39 & 70 & 12.96 & 67 & 13.27 & 354 & 13.13 \\
\hline $55-59$ years & 74 & 12.89 & 53 & 10.43 & 90 & 15.79 & 70 & 12.96 & 70 & 13.86 & 357 & 13.24 \\
\hline $60-64$ years & 78 & 13.59 & 52 & 10.24 & 55 & 9.65 & 63 & 11.67 & 57 & 11.29 & 305 & 11.31 \\
\hline Total & 574 & 100 & 508 & 100 & 570 & 100 & 540 & 100 & 505 & 100 & 2,697 & 100 \\
\hline \multicolumn{13}{|l|}{ MaritalStatus } \\
\hline monogamous & 359 & 62.54 & 313 & 61.61 & 347 & 60.88 & 310 & 57.41 & 313 & 61.98 & 1642 & 60.88 \\
\hline Polygamous & 82 & 14.29 & 82 & 16.14 & 87 & 15.26 & 91 & 16.85 & 71 & 14.06 & 413 & 15.31 \\
\hline informal union & 2 & 0.35 & 2 & 0.39 & 1 & 0.18 & 2 & 0.37 & - & - & 7 & 0.26 \\
\hline Divorced & 3 & 0.52 & 5 & 0.98 & 6 & 1.05 & 8 & 1.48 & 4 & 0.79 & 26 & 0.96 \\
\hline Separated & 20 & 3.48 & 12 & 2.36 & 19 & 3.33 & 18 & 3.33 & 14 & 2.77 & 83 & 3.08 \\
\hline Widowed & 64 & 11.15 & 62 & 12.20 & 74 & 12.98 & 67 & 12.41 & 66 & 13.07 & 333 & 12.35 \\
\hline never married & 44 & 7.67 & 32 & 6.30 & 36 & 6.32 & 44 & 8.15 & 37 & 7.33 & 193 & 7.16 \\
\hline Total & 574 & 100 & 508 & 100 & 570 & 100 & 540 & 100 & 505 & 100 & 2,697 & 100 \\
\hline \multicolumn{13}{|l|}{ Householdsize } \\
\hline $1-5$ persons & 149 & 25.96 & 121 & 23.82 & 152 & 26.67 & 155 & 28.70 & 149 & 29.50 & 726 & 26.92 \\
\hline $6-10$ persons & 223 & 38.85 & 225 & 44.29 & 223 & 39.12 & 198 & 36.67 & 200 & 39.60 & 1069 & 39.64 \\
\hline
\end{tabular}




\begin{tabular}{|c|c|c|c|c|c|c|c|c|c|c|c|c|}
\hline $1-15$ persons & 100 & 17.42 & 82 & 16.14 & 111 & 19.47 & 115 & 21.30 & 82 & 16.24 & 490 & 18.17 \\
\hline 15 and above & 102 & 17.77 & 80 & 15.75 & 84 & 14.74 & 72 & 13.33 & 74 & 14.65 & 412 & 15.28 \\
\hline Total & 574 & 100 & 508 & 100 & 570 & 100 & 540 & 100 & 505 & 100 & 2,697 & 100 \\
\hline
\end{tabular}

Source: Authors Computation

The Table shows that there respondents were more males in the region. At the states level, the females are 83, 84, 83, 94 and 71, representing 14.46, 16.56, 14.56, 17.41 and 14.06 percent for Abia, Anambra, Ebonyi, Enugu and Imo states respectively. Of the respondents age range, 10 or 0.37 per cent of the respondents were between the age range 25-29 years, 60 or 2.22 per cent were between the age range 30-34 years, 178 (6.6) per cent were between the age range 35-39 years, 285 (10.6) per cent were between the age range 40-44 years and $311(11.5)$ were between the age range of 45-49 years. Those between the age range of $50-54$ years were 354 (13.1), 55-59 years were 357 (13.2), and 60-64 years were 305 (11.3) per cent. 186 (6.9) per cent were between the age range of 65-69 years, while 650 (24.1) per cent were between the age range of 70 years and above. At the states level, 130 (22.7) per cent, 137 (26.9) per cent, 133 (23.3) per cent, 126 (23.3) percent and 124 or (24.6) percent were between the age range of 70 years and above respective for Abia, Anambra, Ebonyi, Enugu and Imo states.As further indicated in Table 1, 1642 (60.9) per cent of the respondents were into monogamous marriage, 413 (15.3) per cent were polygamous, and 7 representing 0.26 per cent were in informal union. 26 (0.9) per cent of the respondents were divorced, 83 (3.1) per cent of the respondents were separated, 333 (12.4) per cent of the respondents were widowed, while $193(7.2)$ per cent were never married. In terms of household size, the Table indicates that 726 (26.9) per cent had a household size of 1-5 persons, 1069 (39.6) 6-10 persons, 490 or (18.2) per cent 11-15 persons while 412 (15.3) 15-20 persons. Similarly, majority of the respondents' households were between 6-10 persons for Abia, Anambra, Ebonyi, Enugu and Imo states respectively.

The distribution of mean healthcare expenditure and mean income in the Southeast region were also determined and the result presented in Table 2 .

Table 2.

Distribution of mean healthcare expenditure and mean incomes

\begin{tabular}{|l|l|l|l|l|}
\hline State/Zone & $\begin{array}{l}\text { Sub-Sample } \\
\text { Population }\end{array}$ & $\begin{array}{l}\text { Mean total Exp. } \\
\text { on health }\end{array}$ & $\begin{array}{l}\text { Mean pre-health } \\
\text { payment income }\end{array}$ & $\begin{array}{l}\text { Mean payment income } \\
\text { payt-health }\end{array}$ \\
\hline Abia & 574 & 21723.87 & 68928.66 & 51966.85 \\
\hline Anambra & 508 & 17755.93 & 72977.89 & 55221.96 \\
\hline Ebonyi & 570 & 26101.97 & 69744.52 & 43642.55 \\
\hline Enugu & 540 & 20332.6 & 67532.36 & 47199.76 \\
\hline Imo & 505 & 18645.24 & 62821.43 & 44176.19 \\
\hline SE Region & 2697 & 21046.75 & 68440.67 & 48407.43 \\
\hline
\end{tabular}

Source: Authors computation

Table 2 reports that the Southeast mean total healthcare expenditure was 1046.75 while the mean prehealthcare payment and the post-healthcare payment mean incomes were 68440.67 and 48407.43 respectively. In each state, there are differences in the distribution of mean healthcare expenditure, the mean pre-healthcare payment and the post-healthcare payment mean incomes. Ebonyi has the highest mean healthcare expenditure of $\$ 26101.97$ followed by Abia with mean healthcare expenditure of 121723.87 . Anambra state has the lowest mean healthcare expenditure of 17755.93 . On the other hand, Anambra state has the highest pre-healthcare payment and the post-healthcare payment means incomes of $\$ 72977.89$ and \$55221.96 respectively. Ebonyi state has the second highest mean pre-healthcare payment income of $\$ 69744.52$ followed by Abia, Enugu and Imo states respectively with mean pre-healthcare payment incomes of 68928.66 , 67532.36 and $\$ 62821.43$.

Table 3

Distributional summary statistics of quintile distribution of post-healthcare payment income

\begin{tabular}{|l|l|l|l|l|l|}
\hline $\begin{array}{l}\text { Quintile } \\
\text { group }\end{array}$ & Quintile & $\begin{array}{l}\text { \% } \\
\text { median }\end{array}$ & $\begin{array}{l}\text { \% quintile group share } \\
\text { of income }\end{array}$ & $\begin{array}{l}\text { \% cumulative } \\
\text { group share }\end{array}$ & $\begin{array}{l}\text { cumulative group share } \\
\times \text { mean (income) }\end{array}$ \\
\hline 1 & 23265.395 & 50.431 & -16.943 & -16.943 & -8201.605 \\
\hline 2 & 46133.332 & 100.000 & 17.935 & 0.992 & 480.168 \\
\hline 3 & 78041.984 & 169.166 & 31.097 & 32.089 & 15533.319 \\
\hline 4 & & & 67.911 & 100.000 & 48407.427 \\
\hline
\end{tabular}

Source: Authors Computation 
The post-healthcare payment income for the $1^{\text {st }}$, $2^{\text {nd }}$ and $3^{\text {rd }}$ quintile groups were 23265.395 or 50.43 per cent of median, 46133.332 or 100.00 per cent of median and 78041.984 or 169.2 per cent of median respectively. The percentage post-healthcare payment income difference between the poorest income group and the middle-income group was found to be 49.6 per cent while the percentage post-healthcare payment income difference between the group immediately after the middle-income group and the middle-income group itself was 69.2 per cent. This indicates that the post-healthcare payment income of the poorest percentage of the population was 49.6 per cent below the post-healthcare payment income of the middleincome group of the population, whereas, the middle group was 69.2 per cent below the post-healthcare payment income.

Table 4.

Redistributive effects of healthcare payment

\begin{tabular}{|l|l|l|l|l|l|l|}
\hline Redistribution Parameters & Aversion Parameter v & \multicolumn{4}{l|}{} \\
\hline & 1.5 & 2 & 3 & 4 & 5 & 6 \\
\hline $\mathrm{G}_{\mathrm{bp}}$ & 0.277 & 0.410 & 0.548 & 0.625 & 0.675 & 0.712 \\
\hline $\mathrm{G}_{\mathrm{ap}}$ & 0.486 & 0.775 & 1.177 & 1.487 & 1.755 & 1.997 \\
\hline $\mathrm{V}$ & -0.055 & -0.084 & -0.115 & -0.132 & -0.145 & -0.157 \\
\hline $\mathrm{R}$ & 0.154 & 0.281 & 0.514 & 0.730 & 0.934 & 1.128 \\
\hline $\mathrm{V}-\mathrm{R}$ & -0.209 & -0.365 & -0.629 & -0.862 & -1.080 & -1.285 \\
\hline
\end{tabular}

Note: $v$ indicates aversion parameter, $G_{b p}$ is the prepayment Gini Index, $G_{a p}$ is the post-payment Gini index, $V$ is the measure of progressivity or vertical equity $\mathrm{R}$ is the index of re-ranking, $(\mathrm{V}-\mathrm{R})$ is the composite index

Source: Author's computation

The estimated values of pre-healthcare-payment Gini Index in Table 4 shows that when the social decision-maker prefers inequity $(\mathrm{v}=1.5)$, the level of pre-healthcare payment income inequity is 0.277 . This is still quite high. At $\mathrm{v}=2$, where the social decision-maker is inequity neutral (which is the standard Gini Index), the level of pre-healthcare payment income inequity is estimated to be very high at 0.410. An increase in the inequity aversion parameter also results in an increase in the predicted pre-healthcare payment income inequities. In addition, the estimated values of the post-healthcare-payment income Gini Indices are higher than the pre-healthcare payment Gini indices. This means that the payment for healthcare contributes to income inequity. Specifically, the level of post-healthcare payment income inequity is 0.486 when the social decision-maker prefers inequity $(\mathrm{v}=1.5)$. The standard Gini Index for the post-healthcare-payment income Gini index is 0.775 , which is 0.365 higher than the pre-healthcare payment income Gini index. This means that the income inequity because of healthcare payment almost doubled the inequity level without healthcare payment. Conversely, the redistributive index is negative; an indication that the health care payment structure worsens the healthcare financing inequity and, therefore, the original pre-payment income inequality in the Southeast region. That is, the healthcare payment system increases income inequality in the redistribution after paying for healthcare (healthcare payment structure is regressive). Healthcare payments at similar levels of income still induce some horizontal inequity and re-ranking. This finding is contrary to the findings of Ichoku, Fonta \& Leibbrandt (2014) that out of pocket health financing is progressive in the Southeast region. The regressive health care payment structure varies with the level of social aversion to income inequality. As $(\mathrm{V})$ increases, the regressive index also increases (more pronounced), which means that the regressive health care payment structure in the region do not redistribute systematically more when the social decision-maker moves from been inequity neutral to inequity averse in healthcare financing. This supports the supposition that an initially unequal distribution and the social choice to redistribute rather little is probably depends on the same underlying factors, strong emphasis on individual responsibility and a big confidence in the health care financing system. The re-ranking index further indicates that individuals move out of their prepayment income class to other classes due to the effects of healthcare payment. Most households are re-ranked in the redistributive process which arises as a result of any changes in rank induced by the healthcare payment system.

\section{Conclusion}

This study sought to examine Progressivity and the re-ranking effect of healthcare financing in South East Nigeria. Empirical findings indicate that health care financing system in the region is regressive, indicating an unfair healthcare payment system that impoverishes poor households. The health care financing 
system is capable of placing households just above the poverty line and those already into poverty to get deeper into it. This is because households that spend more on healthcare cannot maintain their original social positions. Such is certainly catastrophic it takes a huge proportion of the household's income and directs it to health care, with very small amount left on other basic needs. The obvious implication is that, in the absence of effective government intervention in health care financing, the average household would fall deeper into poverty.

\section{References}

Abu-Zaineh, M., A. Mataria, S. Luchini, \& J. Moatti (2008), Equity in health care financing in Palestine: The value-added of the disaggregate approach. Social Science \& Medicine, 66: 2308-2320

Ademiluyi, I. A. \& S. O. Aluko-Arowolo (2009), Infrastructural distribution of healthcare services in Nigeria: An overview. Journal of Geography and Regional Planning, 2(5): 104 - 110

Akaziliet, A., B. Garshong, M. Aikins, J. Gyapong, \& D. McIntyre (2012), Progressivity of health care financing and incidence of service benefits in Ghana. Health Policy and Planning, 27: 113-122

Almasiankia, A., Z. Kavosi, A. Keshtkaran, B. Jafari, \& S. Goodarzi (2015), Equity in health care financing among Rranian households. Shiraz E-Medical Journal, 16 (11): $1-7$

Aronson, J. R., P. Johnson, \& P. J. Lambert (1994), Redistributive effect and unequal income tax treatment in the U.K. The Economic Journal, 104: 262-270

Asante, A., J. Prince, A. Hayen, S. Jan Jan \& V. Wiseman (2016), Equity in health care financing in low-and middle-income countries: A systematic review of evidence from studies using benefit and financing incidence analyses, PLoS ONE, $11(4):$ eO 152866

Asante, A. D., J. Price, A. Hayen, W. Irava, J. Martins, L. Guinness, J. E. Ataguba, S. Limwattananon, A. Mills, S. Jan \& V. Wiseman (2014), Assessment of equity in healthcare financing in Fiji and Timor-Leste: a study of protocol, Journal of Neuo Interventional Surgery, 4 (2): 262-270

Ataguba, J. E. \& J. Akazili (2010), Health care financing in South Africa: Moving towards universal coverage. CME, 28(2): 74-78

Burger, R., C. Bredenkamp, C. Grobler, \& S. van der Berg (2012), Have public health spending and access in South Africa become more equitable since the end of apartheid? Development Southern Africa, 29, 681-703

Chen, M., G. Fang, L. Wang, Z. Wang, Y. Zhao, \& L. Si (2015), Who benefits from government healthcare subsidies? An assessment of the equity of health care benefits distribution in China. Plos One, 10, 119-134

Cheng, S. \& J. S. Long (2007), Testing for IIA in the multinomial logitmodel, Sociological Methods \& Research, 35(4): 583-600

Chotikapanich, D. \& W. Griffiths (2000), On calculation of the extended Gini coefficient. University of New England, School of Economic Studies Working Paper Series in Econometrics and Applied Statistics, No. 1.Available from: http://www.une.edu.au/febl/EconStud/wps.htm

Donaldson D. and J. Weymark (1983), Ethically flexible Gini indices for income distributions in the continuum. Journal of Economic Theory, 29(2): 353-358

Donaldson, D. \& J. Weymark (1980), A single-Parameter Generalization of the Gini Indices of Inequality. Journal of Economic Theory, 22(1): 67-86

Ghosh, S. (2014), Equity in the utilization of healthcare services in India: evidence from National Sample Survey. International Journal of Health Policy Management, 2(1): 29-38

Gisbert, F. J. G., M. L. de la Vega \& A. M. Urrutia (2010), Generalizing the S-Gini family: Some properties. ECINEQ Working Paper Series No. 170, available from www.ecineq.org

Hidayat, B., H. Thabrany, H. Dong\& R. Sauerborn (2004), The effects of mandatory health insurance on equity in access to outpatient care in Indonesia. Health Policy and Planning 19(5), 32- 335

Ichoku, H. E., W. M. Fonta\& M. Leibbrandt (2011), Can out-of-pocket health financing be fair? Empirical evidence from Nigeria. Asian-African Journal of Economics and Econometrics, 11(1), 89-111

Ichoku, H. E. \& W. M. Fonta (2006), The distributional impact of healthcare financing in Nigeria: A case study of Enugu state. PMMA working paper No. 17

Ichoku, H. E., W. M. fonta, \& O. Onwujekwe (2009), Incidence and intensity of catastrophic healthcare financing and impoverishment due to out-of-pocket payments in southeast Nigeria, available from https://www.researchgate.net/publication/52000176

Jędrzejczak, A. (2010), Estimation of income inequality measures by regions on the basis of polish HBS. University of Lodz. Available at: $\quad$ http://www.isini2011.uson.mx/articles/Jedrzejczak,\%20A.\%20-

\%20ESTIMATION\%20OF\%20INCOME\%20INEQUALITY\%20MEASURES\%20B.pdf

Jenkins, S. P., \& P. Van Kerm (2006), Trends in income inequality, pro-poor income growth, and income mobility. Oxford Economic Papers, 58: 531-548

John, E. U., A. Y. Agada-Amade, P. G. Oyibo \& I. G. Ugwu (2015), Healthcare financing in Nigeria: A systematic review assessing the evidence of the impact of health insurance on primary health care delivery. Journal of Hospital Administration, 4(1): $1-8$

Khemani, S. (2004), Local government accountability for health service delivery in Nigeria. Development Research Group, the World Bank, Washington, DC. 
Limwattananon, S., V. Vongmongkol, P. Prakongsai, W. Patcharanarumol, K. Hanson, V. Tangcharoensathien\& A. Mills (2011), The equity impact of Universal Coverage: health care finance, catastrophic health expenditure, utilization and government subsidies in Thailand. An output of the Consortium for Research on Equitable Health Systems

McIntyre, D. (2007), Learning from experience: Health care financing in low- and middle-income countries. Global Forum for Health Research. Available from: www.globalforumhealth.org

Mills, A., J.Ataguba, J.Akazili, J.Borghi, B.Garshong, S.Makawia, G.Mtei, B. Harris, J. Macha, F. Meheus\& D. McIntyre (2012), Equity in financing and use of health care in Ghana, South Africa, and Tanzania: Implications for paths to universal coverage. Available from: www.thelancet.com

Mondal, S. (2014), Health policy changes and their impact on equity of health financing in India. Institute for Studies in Industrial Development Working Paper No. 163. Available at: http://isid.org.in

Moradi, A. (2012), Equity of health care financing: an application to Iran. International Research Journal of Applied and Basic Sciences, 3(5): $2626-2632$

Ohadi, E., M. El-Khoury, T. Williamson \& D. Brinkerhoff (2012), Public budgeting and expenditure management in three Nigerian states: Challenges for health governance. U.S. Agency for International Development (USAID). Available at: www.healthsystems2020.org

Okech, T. C. (2014), Systematic review of kenya's programmatic progress towards universal coverage and its effect on health equity. International Journal of Business and Social Science, $5(7): 73-82$

Olakunde, B. O. (2012), Public health care financing in Nigeria: Which way forward? Ann Nigerian Medcine, 6(1): 4-10

Omoluabi, E. (2014), Promoting Better Management of Migration in Nigeria: needs assessment of the Nigerian health sector. Abuja: international organization for migration

Onuoha, C. M. (2008), Imperative of South East Nigeria Economic Commission (SENEC). Available from: http://www.senec.org.ng/senec/index.php/news/36-news-events/57-imperative-of- $\quad$ south-east-nigeriaeconomic-commission-senec

Onwujekwe O., B. Uzochukwu, \& C. Onoka (2011), Assessing the use and cost of healthcare services and catastrophic expenditures in Enugu and Anambra states, Nigeria. Consortium Research on Equitable Health Systems (CREHS) Policy Brief. Available from: $\quad$ http://www.crehs.lshtm.ac.uk

Oyekale, A. S., A. I. Adeoti, \& T. O. oyekale (2006), Measures and sources of income inequality in rural and urban Nigeria. A Report Submitted to the Poverty and Economic Policy Network, Universite Laval, Canada

Or, Z., F. Jusot, \& E. Yilmaz (2008), Impact of health care system on socioeconomic inequalities in doctor use. European Union Working Group on Socioeconomic Inequalities in Health Working Paper No 17. Available from: www.irdes.fr

Prinja, S., A. Aggarwal, R. Kumar\& P. Kanavos (2012), User charges in health care: evidence of effect on service utilization \& equity from north India. Indian $J$ Med Res, 136: 868-876

Rannan-Eliya, R. P., C. Blanco-Vidal\& A. K. Nandakumar (2000), The distribution of health care resources in Egypt: implications for equity

Rashad, S. R. \&M. F. Sharaf, (2015), Who Benefits from Public Healthcare Subsidies in Egypt? Social Sciences, 4, $1162-1176$

Rezapour, A., F. E. Azar, S. A.Ghdash, A. T. Tanoomand, S. M. H. Shokouh, N. Yousefzadeh, P. A. Manesh, \& A. S. Asiabar (2015), Measuring equity in household's health care payments (TehranIran 2013): technical points for health policy decision makers. Medical Journal of the Islamic Republic of Iran, 29(246): 1 - 10

Riman, H. B. \& E. S. Akpan (2012), Healthcare financing and health outcomes in Nigeria: A state level study using multivariate analysis. International Journal of Humanities and Social Science, 2(15): 296-308

Schneider, P. \& K. Hanson (2006), Horizontal equity in utilization of care and fairness of health financing: A comparison of micro-health insurance and user fees in Rwanda, Health Economics, 15: 19-31

Uzochukwu, B. S. C., B. E. Onwujekwe\& N. Ezumah (2014). The district health system in Enugu $\quad$ state, $\quad$ Nigeria: An analysis of policy development and implementation, African Journal of $\quad$ Health Economics, 3(1): 1-14

Wagstaff, A., M. Bilger, L. Buisman\& C. Bredenkamp (2014). Who benefits from government health spending and why? A global assessment. Available from: http://papers.ssrn.com/sol3/Papers.cfm?abstract_id=2500586 Accessed on 10 November 2016

Wagstaff, A. (2001). Measuring equity in health care financing; Reflections on (and alternatives to) the World Health Organization's fairness of financing index, Policy Research Working Paper, $\quad$ No. 2550, World Bank, Washington, DC, available from http:llopenknowledge.worldbank.org/handle/10986/19962, Accessed on 3rd December 2018

William, M. K. (2011). Motivation and job commitment among teachers in four selected senior high schools in the Ashanti region of Ghana. Master's Thesis, Institute of Distance Leaning, Knust

Wouters, O. J., J. Cylus, W. Yang, S. Thomson, \& M. McKee (2016), Medical savings accounts: Assessing their impact on efficiency, equity, and financial protection in health care, Health Economics, Policy and Law, 1-15. Available from: http://eprints.lse.ac.uk/65448/

Yitzhaki, S. (1983), On an extension of the Gini Inequality Index. International Economic Review, 24(3): 617-627

Yu, C.P., D. K. Whynes \& T. Sach (2008), Equity in healthcare financing: The case of Malaysia, International Journal for Equity in Health, 7 (1): 15

Yunusa, U., O. Irinoye, A. Suberu, A. M. Garba, G. Timothy, A. Dalhatu\& S. Ahmed (2014), Trends and challenges of public health care financing system in Nigeria: The way forward. IOSR Journal of Economics and Finance, 4(3): 28-34 